\title{
Effect of Lights and Colors on the Environmental Perception and Legibility Using Augmented Reality Technology
}

Iranian Evolutionary and Educational Psychology Journal

September 2020: 148-159

(C) University of Hormozgan Publication 2020

DOI: 10.29252/ieepj.2.3.148

http://ieepj.hormozgan.ac.ir

\author{
Ahmadreza Khalili', Hossein Soltanzadeh ${ }^{2 *}$, S. Hadi Ghoddusifar ${ }^{3}$
}

\begin{abstract}
One's cognitive perception of the environs is in direct relationship with their subjective mental image of the surroundings. Various elements influence the perception and legibility of the environment before human mind. Among these elements are the light and color of the environs. The question is which light or color spectrum is capable of heightening the legibility and spatial perception of the given environment for users. Considering that, the aim of the present study is first to examine the effect of lights and colors on the legibility rate of interior spaces, and then, to identify the reasons users have chosen them. To this end, authors have used augmented reality technology to simulate a variety of environments based on different light and color parameters. A group of 120 students from the Faculty of Art and Architecture of Islamic Azad University, West Tehran Branch, collaborated with the authors to carry out the study. For the purpose of the experiment, the interior of the faculty building was simulated using 3D software and was put through experience and evaluation by using augmented reality technology. Eventually, the students were asked to select those environments they deemed as featuring more perception and legibility than others. The participants' spatial perception was tested by assigning the type of the environment as the dependent variable. Color, light, and gender were examined as the independent variables. Chi-square test was used to determine the difference between the frequencies of the environments selected by the participants. Results showed that neutral color was more attractive than the other two color spaces. There was no significant difference between three color spaces in terms of guidance and invitation. Generally, the participants preferred neutral color over the other two colors. In other words, neutral color was better perceived than the other two because of its greater attractiveness.
\end{abstract}

Keywords: Perception and legibility of the environment, light and color, interior space, augmented reality technology.

\section{Introduction}

As realities flow through the brain, one chooses certain ones to recognize them as objective. Thus far, the perception remains at the abstract level. However, once the mind converts the objective perception into a subjective notion, it starts using the latter as a criterion of evaluation and enters the tangible level of life to opt for the appropriate response to the situations (Pakzad \& Bozorg, 2014). Therefore, one's cognitive perception of the environs is in direct relationship with their mental image of the surroundings. Various elements factor in the perception and legibility of the environment before human mind. Among these elements are the

1. Ph.D. Candidate of Architecture, Department of Architecture, Faculty of Art \& Architecture, South Tehran Branch ,Islamic Azad University, Tehran, Iran.

2. Associate Prof, Department Of Architecture, Architecture and Urban Design Faculty, Central Tehran Branch, Islamic Azad University, Tehran, Iran, *Corresponding author email: h72soltanzadeh@gmail.com

3. Assistant Prof, Department of Architecture, Faculty of Art \& Architecture, South Tehran Branch, Islamic Azad University, Tehran, Iran. 
environmental factors in the surrounding that are perceived by five senses. Examples of such factors are light and color, which are received and processed by eyes. Mental image is considered a subjective and intangible concept. As a result of interaction between humans and the environment, mental images are composed of one's mental awareness of the environment (Tantanatewin, 2016). Therefore, the study of mental images is the first step to analyze interactions between humans and the environment which is known as "inside-out" which complements outside-in view. Mental images are a set of images formed from the appearance, function, and meaning of a space in the mind (Read, 2003). As one of the three aspects of space changes, mental images also change with time. Therefore, as the interpretations, mental images and meanings formed for people are unique depending on the values, priorities and experiences, and their behavior relative to a similar situation varies too (Yildirim, 2007).

Most studies conducted in this field only deal with one aspect, i.e. the light or the color of the space. However, the present study investigated the color and light of space together. Another innovative aspect of this study was the use of augmented reality technology. In fact, the aim of the present study is first to examine the effect of lights and colors on the legibility rate of interior spaces, and then, to identify the reasons users have to choose them.

To this end, researchers have employed augmented reality technology to simulate a variety of environments based on different light and color parameters. The statistical population of this research is comprised of undergraduate students of West Tehran Branch, IAU. The question posed as follows: from among the experienced environments, which one featured the highest legibility and perception. The other question was regarding the reason the participants had (attractiveness, sense of invitation, or navigation) for their choice. Gender has been taken into account while conducting the experiment along with a quantitative study of the effect of environmental factors, such as light and color, on the perception and legibility of the surroundings for the participants

\section{Literature Review}

A review of pertinent literature indicates that different colors have different effects on people. According to Stone (2003), warm colors attract people to the exterior and heightens their alertness. Differently, cool colors draw attention towards the interior and help people concentrate on mental and visual issues. As put by Stone and English (1998), cool colors bring about tranquility and warm colors stimulate emotions. Elsewhere in a study carried out by Bebin (2013), blue was perceived as more positive than orange, and seemed to have a greater influence in purchase decision-making. Similarly, Bellizzi (1983) states that stores decorated with cool colors were preferred over those with warm ones. Akalin (2009) discusses that purple was a better-received color than yellow for the inside of a bakery.

Likewise, Valdez's (1994) research shows that colors of shorter wavelengths (cool colors like purple and blue) are chosen over those with longer wavelengths (warm colors like yellow and orange). Camgöz et al (2004) have suggested that when colors are bright and saturated, their attractiveness increases.

Read (2003) believes that warm, bright colors heighten individuals' perception. Similarly, Canter underlines the attractiveness of warm colors, stating that red makes objects appear closer compared to blue. In fact, it is believed that use of warm colors facilitates people's perception of the space (Canter, 1983).

According to kenz and kers, interior ambient lighting works directly on the emotions, memories, perceptual navigation, and problem-solving skills (Knez \& Kers, 2000). Meanwhile, Muci (1994) reiterates that lighting techniques helps people with navigation around places. Mahnke and Mahnre (1993) realized that spaces with 
more neutral tones (gray and white) were observed as sterile and dull by the attendants, while spaces with a warm color (red) reflected a high rate of attractiveness. Therefore, the research presumes that increased harmony among the colors of a given interior results in a more positive perception of the space. Kumoglu Suzer, et al. (2018) found that subjects reported a more positive mood under 2000 than under 300 lux. Tantanatewin (2016) proposed a model in which mood, visual performance and decisionmaking strategy are affected by the visual environment for mental processing capacity. The mood shift for women was strongly negative for bright conditions and near zero for 'dim' conditions, whereas men tended to respond in the opposite direction. Quartier et al (2014) found that age and gender interacted with the illuminance and the colour temperature of the lighting, causing different kinds of mood shifts. Wardono et al. (2012) showed the existence of systematic influences on mood from lighting parameters within the range encountered in everyday interior conditions. Given the review of relevant literature, it was revealed that there was no record of prior research work in which the effect of the two parameters of light and color in various environments were examined. The present study would review the two parameters as well as the reason for the choices of environment based on the environmental indicators of attractiveness, sense of invitation, and navigation.

\section{Theoretical foundation}

Perception and legibility: Legibility is the quality which makes a place perceivable and can affect the ease and manner of people's understanding of the chances and opportunities they are presented by the given environment (Lynch, 1960). To Bentley, legibility is what makes a place graspable, and it is significant at two levels of physical form and pattern (Bentley, 1985). Elsewhere, a legible environment is defined as one that features qualities responsive to aesthetic, safety, and navigation needs (Bellizzi, Crowley, \& Hasty, 1983).

To Erem and Sener (2008), legibility is a variable of the environment which is used to read its surroundings. Paydar (2012) describes it as a feature of the environment which helps the individual to tangibly locate themselves along the path. The quality of this feature for pedestrians depend on how familiar they are with the environs. The important point in the organization of a legible environment is to form an accurate, clear concept of the respective qualities in the mental image of the audience.

Environmental elements affected by the perception and legibility of the environs: Mahdzar and Safari (2014) express that simplicity of the place and spatial organization are pertinent to 2-dimensional data about the space. In fact, legibility is subordinate to the spatial geometry. Likewise, Höllerer and Feiner (2004) believe that legibility is the staple of designing interior spaces and determines how the built environment must be organized in order to establish the mental image, coherence, and visibility. The quality of legibility depends on visibility, simplicity, connectivity, unity, and the ability to perceive all these in a given structure (Höllerer\& Feiner, 2004). Baker (1986) categorizes the factors of interior space as follows: The environs (temperature, sound, scent), design (plan, colors, material, and furniture arrangement), and the social factor (age, gender, education) which influence the spatial perception, restriction, and function. Proper application of the environmental factors positively affects the users' perception, behavioral decisions, spatial navigation, and pathfinding. Light and color are among the elements that affect the perception and legibility of the interior spaces (Baker, 1986).

Human eye is one complicated tool to receive optical stimulants. The structure of human eye is comprised of three parts in charge of the sense of sight: One part of the system is dedicated to perception of forms, the second one perceives colors, and the third one receives light and spatial organization. Referring to the signal 
theory, Pile says that environmental conditions can function in increasing or decreasing the legibility, and thus, color and light can influence one's perception of the surroundings. As Pile puts it, the three factors of attractiveness, sense of invitation, and navigation can play a significant role in the improvement of perception and legibility of the environment and can facilitate pathfinding (Pile, 1997). Table 1 summarizes the environmental factors that influence environmental readability from the perspective of experts in this field.

Table 1. Various viewpoints on environmental elements factoring in legibility

\begin{tabular}{|l|l|}
\hline Scholar & \multicolumn{1}{|c|}{ Parameters } \\
\hline Mahdzar and Safari & Simplicity of the place, spatial organization, spatial geometry \\
\hline Dalton and Hölscher & visibility, simplicity, connectivity, unity, and the ability to perceive \\
\hline Baker. & $\begin{array}{l}\text { The environs (temperature, sound, scent), design (plan, colors, material, and furniture } \\
\text { arrangement), and the social factor (age, gender, education) }\end{array}$ \\
\hline Pile & Environmental light and color \\
\hline
\end{tabular}

The present study is based on Pile's theory of environmental elements and color and light in particular, and intends to investigate how they influence the perception and legibility of the faculty interior for the students of architecture. In this method, ambient colors (warm, cool, and neutral colors), light, brightness of ambient lights, and the participants' gender were taken as independent variables, and attractiveness, navigation, and sense of invitation which contribute to the spatial perception as the dependent variables.

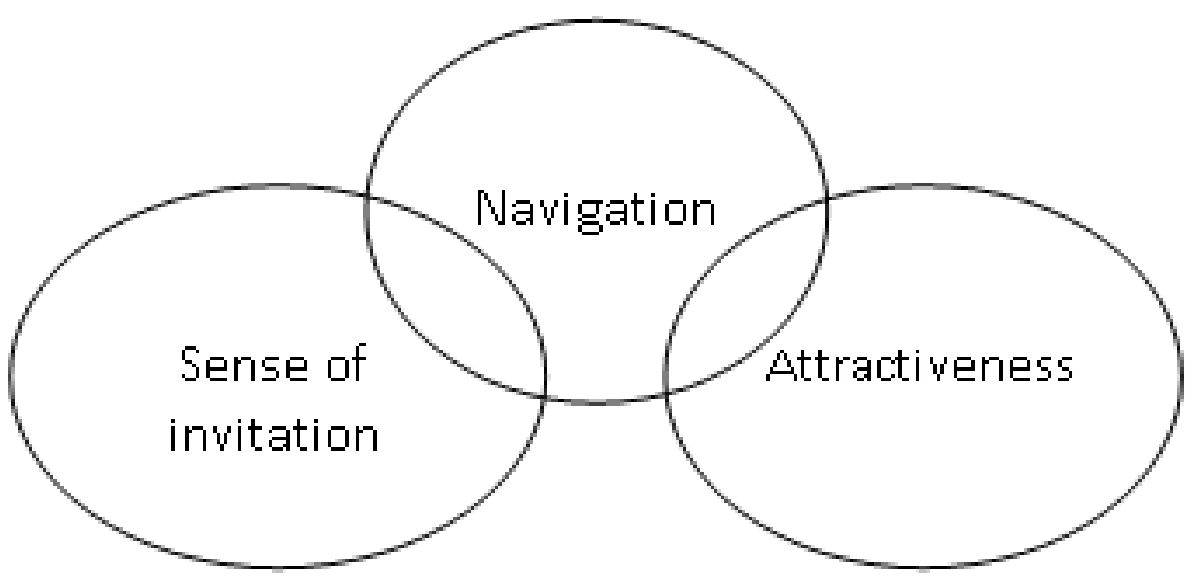

Figure1. The three parameters marked by Pile as the indicators of light and color which affect the perception and legibility of the environs

Environmental perception in Cyberspace: Augmented reality is connected to the concept of virtual reality. Virtual reality is an attempt to create an unreal world to which users can connect by using visual, auditory, and other tools. Augmented reality makes it possible to add complements to the real world instead of creating an artificial environment. In short, augmented reality is the computer-generated items combined with the real-world environs. Azuma (1997) defines the indicators of augmented reality as follows: 1. Superimposing virtual images on an actual space; 2. Simultaneous interaction in real settings; 3. 3-D recording of digital data in the actual space.

Osman (2002) highlights the significance and benefits of using a virtual reality in experimental adjustment, arguing that the structural path and design of a virtual space, the location of a moving or fixed object or the type and form of other variables can be easily altered using a computer program. In a shorter span of time, with 
smaller efforts and at higher costs, tests including the simulation of real-world spaces (analog versions, actual places, full-scale models, etc.) and their comparison to virtual spaces can be run (Osmann, 2002). Kipper and Rampolla prove that virtual spaces can bear the complexities of the real world, and the results of tests conducted in virtual spaces are quite similar to those carried out in real-world environments (Kipper \& Rampolla, 2013). Likewise, Tlauka and Wilsen (1996) noticed that actual and virtual environments were produced using similar maps. Osman and Berendt reiterate that using virtual environments would yield accurate findings and can be carried out at far lower costs compared to creating real-world scenarios (Osmann \& Berendt, 2002). In the same regard, the present study made use of augmented reality in order to simulate a variety of environments based on different light and color parameters.

\section{Material and Method}

Statistical population: A group of 120 students from the Faculty of Art and Architecture of Islamic Azad University, West Tehran Branch collaborated with authors to carry out the study. They were selected out of a group who had not seen the test scenario. In order to achieve reliable statistical results, the year and gender dispersions of the participants were designated similarly: Freshman: $24.5 \%$, sophomore: $25.5 \%$, junior: $24.5 \%$, and senior: $25.5 \%$; female: 50\%, and male: 50\%. The participants were all in the 19-25-year-old age range.

Sampling Method: In this research, Sampling Method is "statistical method" involving the selection of elements from an ordered sampling frame. Statistical methods are mathematical formulas, models, and techniques that are used in statistical analysis of raw research data. The application of statistical methods extracts information from research data and provides different ways to assess the robustness of research outputs. The most common form of systematic sampling is an equiprobability method. In this approach, progression through the list is treated circularly, with a return to the top once the end of the list is passed.

Procedures of data collection and analysis: Participants were expected to experience different light and color conditions in order to discover the effect of light and color on the spatial perception. For accuracy reasons, it was necessary to have a controllable environment in which changes of colors and light densities could be adjusted. It was also required to feature stable environmental details such as materials, textures, and temperature. Therefore, the authors designed a proposed path in Rhinoceros 3D, modeled and simulated it (image 2), and placed the environmental factors in it. After simulation of various environs, each of the participants went through 6 different scenarios (Table 2). Initially, they experienced spaces lit with day light with three different color schemes (warm, neutral, cool). The next 3 scenarios featured various light levels (bright, semi-bright, and dark) in an environment of neutral color (white). Scenarios were carried out using augmented reality technology. At the end, the students were asked to select the environment they deemed more perceivable and legible. Subsequently, they were asked for the reason of their choice drawing upon the three parameters of invitation, navigation, and attractiveness. The participants' spatial perception was tested by assigning the type of the environment as the dependent variable. Color, light, and gender were examined as the independent variables. Chi-square test was used to determine the difference between the frequencies of the environments selected by the participants. The ratio of the expected participants for each category was equal.

Color, intensity of light, and the temperature of colors were determined based on the calculation of references extracted from Pile's research. Thus, various scales of warm colors (red R: 126 G: 0 B: 0), neutral (gray R: 100 G: 100 B: 100), and cool (blue R: 0 G: 0 B: 126), brightness (low (161X), medium (2501X), and high (5001X), and color temperatures (warm white (2700k), neutral white (4000k), and day light (5300k) were 
used (Table 2).

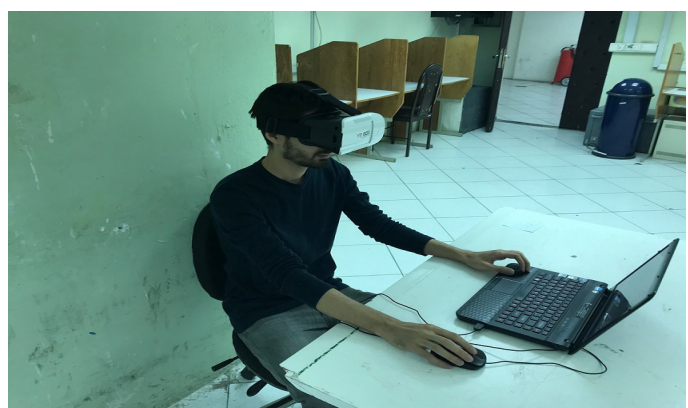

Image 1. Proposed path for simulations based on the interior of the faculty building

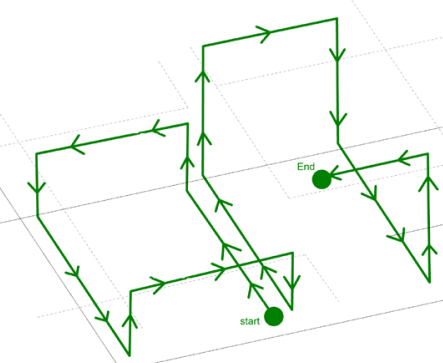

Image 2. Method of using augmented reality technology by the participants

Table 2. Simulation of the interior of the faculty building based on various light and color schemes

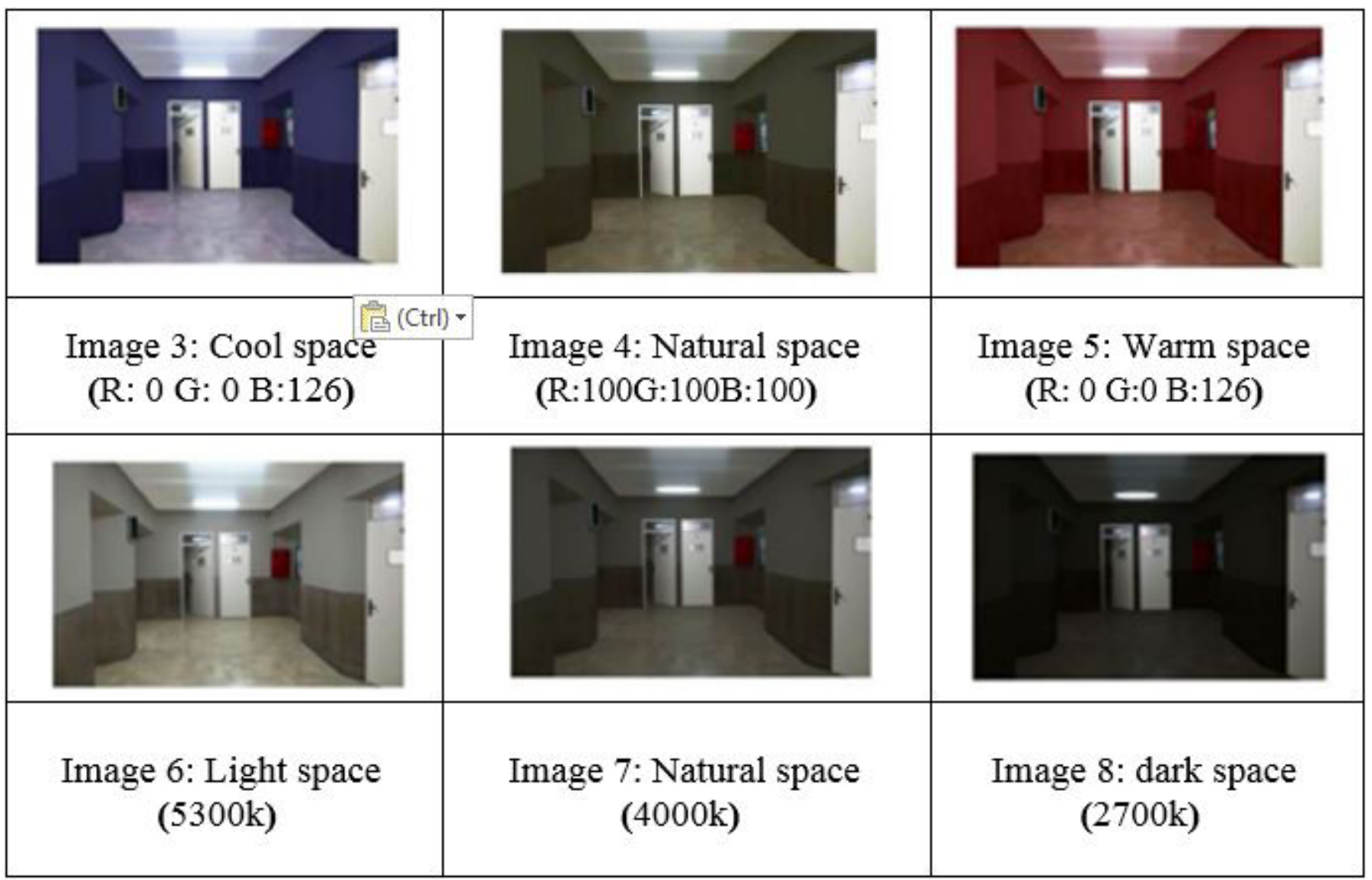

\section{Results}

Results of the participants' choices of colors and their respective categorizations are shown in Tables 3 and 4. Tables 5 and 6 show the light parameter based on the brightness level and the choices made by 120 males and females. The participants' spatial perception was tested by assigning the type of the environment as the dependent variable. Color, light, and gender were examined as the independent variables. Chi-square test was used to determine the difference between the frequencies of the environments selected by the participants. The ratio of the expected participants for each category was equal.

Frequencies and percentage of the choice of various environments based the environment and colors are 
displayed in Table 3. The difference between the frequencies of the three color environments was examined using chi-square test. As evident in the findings, there was a significant difference $\left(\chi^{2}=120.6, \mathrm{df}=2, \mathrm{P}<0.001\right)$ between environments with various color schemes and neutral color was more attractive than the other two. No significant difference was observed between the three-color schemes as for navigation and sense of invitation $\left(\chi^{2}=2.33, \mathrm{df}=2, \mathrm{P}=0.311\right)$. The participants preferred neutral colors to the other two. In other words, the neutral color was better perceived due to its higher attractiveness.

Table 3. Chi-square test to examine the effect of color on the spatial perception

\begin{tabular}{|c|c|c|c|c|c|c|c|}
\hline \multirow[t]{2}{*}{ Type of the environment } & \multicolumn{4}{|c|}{ Frequency (percent) } & \multirow{2}{*}{$\chi^{2}$} & \multirow{2}{*}{$\mathrm{DF}$} & P-Value \\
\hline & Cool & Neutral & Warm & Total & & & \\
\hline Attractiveness & $11(14.9)$ & $50(67.6)$ & $13(17.6)$ & 74 & 39.108 & 2 & $\mathrm{P}<0.001$ \\
\hline Navigation & $6(21.4)$ & $14(50)$ & $8(28.6)$ & 28 & 3.714 & 2 & 0.156 \\
\hline Sense of invitation & $5(27.8)$ & $9(50)$ & $4(22.2)$ & 18 & 2.333 & 2 & 0.311 \\
\hline Total & $22(18.3)$ & $73(60.8)$ & $25(20.8)$ & 120 & 120.6 & 2 & $\mathrm{P}<0.001$ \\
\hline
\end{tabular}

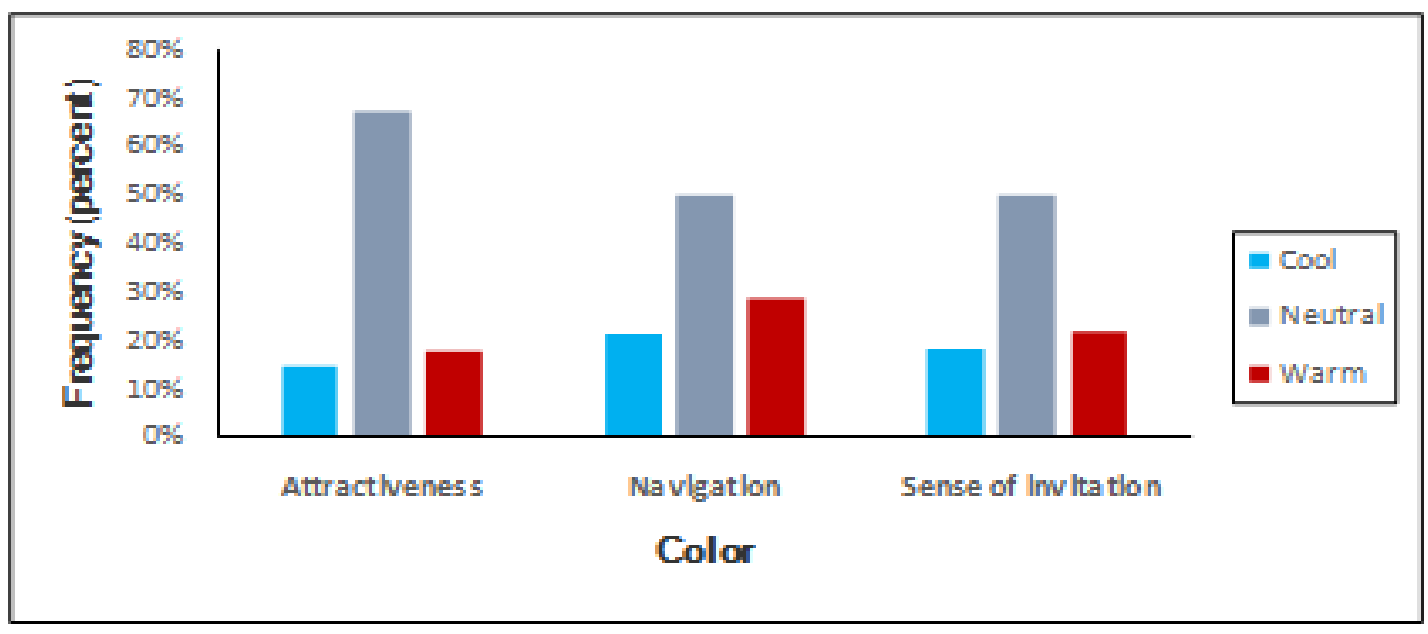

Figure 2. Effect of colors on spatial perception

The difference between the frequencies of the three color environments based of gender is displayed in Table 4. The difference between the frequencies of environments chosen by either gender is significant $\left(\chi^{2}=40.95\right.$, $\mathrm{df}=2, \mathrm{P}<0.001$ ). Both gender groups chose the neutral environment over the cool or warm ones.

Table 4. Chi-square test to examine the color preferences based on gender

\begin{tabular}{|c|c|c|c|c|c|c|c|}
\hline \multirow{2}{*}{ Sex } & \multicolumn{4}{|c|}{ Frequency (percent) } & $\chi^{2}$ & \multirow{2}{*}{$\mathrm{DF}$} & \multirow{2}{*}{ P-Value } \\
\hline & Cool & Neutral & Warm & Total & 19.3 & & \\
\hline Male & $13(21.7)$ & $36(60)$ & $11(18.3)$ & 60 & 22.3 & 2 & $\mathrm{P}<0.001$ \\
\hline Female & $9(15)$ & $37(61.7)$ & $14(23.3)$ & 60 & 40.95 & 2 & $\mathrm{P}<0.001$ \\
\hline Total & $22(22.3)$ & $73(60.8)$ & $25(20.8)$ & 120 & & 2 & $\mathrm{P}<0.001$ \\
\hline
\end{tabular}




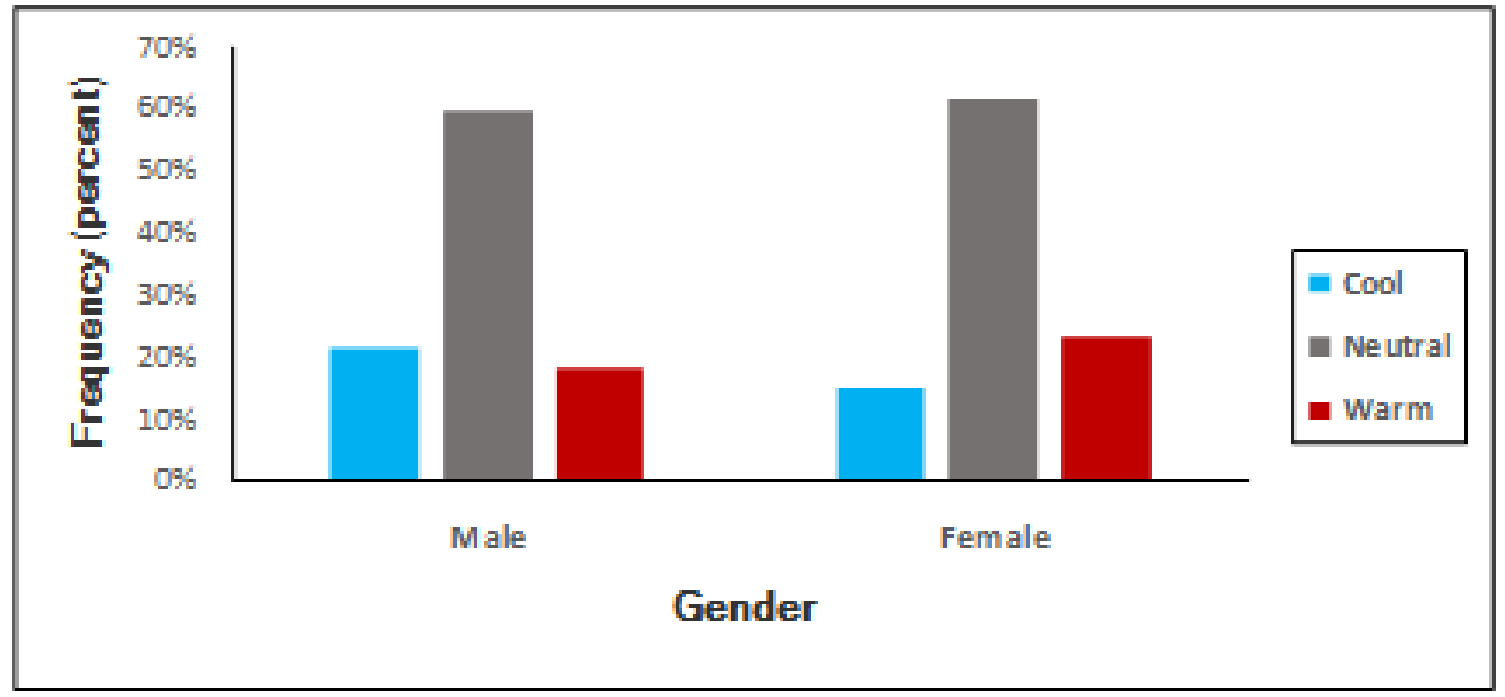

Figure 3. Difference between colors chosen by the two genders

Frequencies and percentage of the choice of various environments based the environment and lights are displayed in Table 5. The difference between the frequencies of the three light environments based on the type of the environment was examined using chi-square test. As evident, the difference between the three lighting schemes was significant regarding the three factors of invitation $\left(\chi^{2}=11.371, \mathrm{df}=2, \mathrm{P}=0.003\right)$, attractiveness $\left(\chi^{2}=14.588, \mathrm{df}=2, \mathrm{P}<0.001\right)$, and navigation $\left(\chi^{2}=8.882, \mathrm{df}=2, \mathrm{P}=0.012\right)$. The participants also preferred semi-transparent light over the other two given the attractiveness regarding the factors of invitation and navigation, the neutral lighting was preferred over the transparent and dark ones.

Table 5. Chi-square test to examine the effect of light on the spatial perception

\begin{tabular}{|c|c|c|c|c|c|c|c|}
\hline \multirow{2}{*}{ Type of the environment } & \multicolumn{4}{|c|}{ Frequency (percent) } & \multirow{2}{*}{$\chi^{2}$} & \multirow{2}{*}{ DF } & \multirow{2}{*}{ P-Value } \\
\cline { 2 - 8 } & Transparent & Semi-transparent & Dark & Total & & & \\
\hline Attractiveness & $15(29.4)$ & $29(56.9)$ & $7(13.7)$ & 51 & 14.588 & 2 & $\mathrm{P}<0.001$ \\
\hline Navigation & $10(29.4)$ & $19(55.9)$ & $4(14.7)$ & 34 & 8.882 & 2 & 0.012 \\
\hline
\end{tabular}

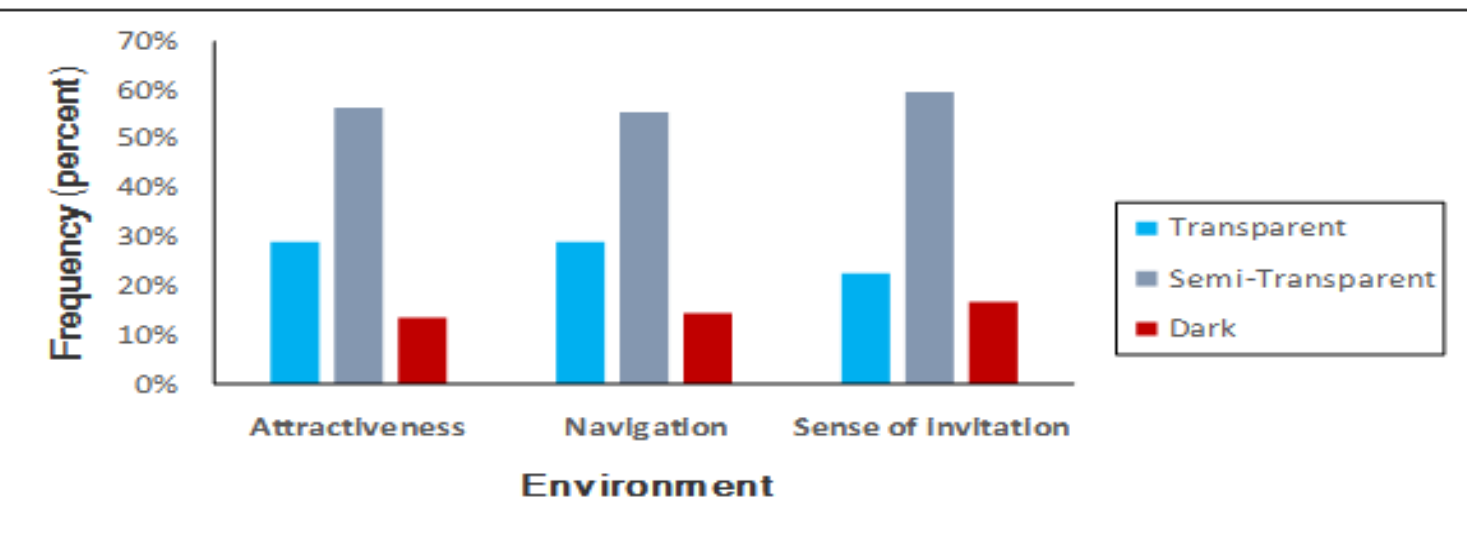

Figure 4. Effect of light on spatial perception 
The difference between the frequencies of the three lighting in the environment based of gender is displayed in table 6 . The difference between the frequencies of environments chosen by either gender is significant of lighting in the environment $\left(\chi^{2}=34.35, \mathrm{df}=2, \mathrm{P}<0.001\right)$. Both gender groups chose the Semi-transparent environment over the Transparent or Dark ones. In the second run, men preferred the darker environment to the transparent, and women preferred the transparent environment.

Table 6. Chi-square test to examine the light preferences based on gender

\begin{tabular}{|c|c|c|c|c|c|c|c|}
\hline \multirow{2}{*}{ Sex } & \multicolumn{4}{|c|}{ Frequency (percent) } & \multirow{2}{*}{$\chi^{2}$} & \multirow{2}{*}{ DF } & \multirow{2}{*}{ P-Value } \\
\hline & Transparent & Semi-transparent & Dark & Total & & & \\
\hline Male & $10(16.7)$ & $36(60)$ & $14(23.3)$ & 60 & 19.6 & 2 & $\mathrm{P}<0.001$ \\
\hline Female & $23(38.3)$ & $33(55)$ & $4(6.7)$ & 60 & 21.7 & 2 & $\mathrm{P}<0.001$ \\
\hline Total & $33(27.5)$ & $69(57.5)$ & $18(15)$ & 120 & 34.35 & 2 & $\mathrm{P}<0.001$ \\
\hline
\end{tabular}



Gender

Figure 5. Difference between colors chosen by the two genders

\section{Discussion}

In this study, the role of color and light of the space on perception and legibility of the interior spaces of Faculty of Art \& Architecture, West Tehran Branch was assessed. The novel method used in this study was augmented reality to create a spatial experience in participants. In this method, at first all circulation routes of the faculty building were modeled by using Rhinoceros software, and then, 6 scenarios were investigated based on different lights and colors. The participants were asked to choose their spatial priorities based on the legibility and perception of the environment according to its guidance, invitation and attractiveness. Then, data were analyzed by using chi-square. Results showed that neutral color was more attractive than the other two color spaces. There was no significant difference between three color spaces in terms of guidance and invitation. Generally, the participants preferred neutral color over the other two colors. In other words, neutral color was better perceived than the other two because of its greater attractiveness. Finally, among the different light spaces, the participants found the semi-transparent light more attractive than the other two in terms of 
attractiveness, guidance and invitation. In addition, neutral light was recognized as superior to the transparent and dark lights in terms of guidance and invitation.

Also, spaces having low brightness level (10 lx) were perceived by the participants of this study rather negatively as compared to other brightness levels (250 lx and $500 \mathrm{~lx}$ ). As the brightness level increased, the space was more positively perceived. When the space was chosen according to brightness levels with respect to the prospect of making orientation decisions in a building entered for the first time, spaces with low-brightness level were not preferred. With increased brightness levels, orientation preferences also increased. The perceptions of participants concerning correlated color temperatures were quite similar. However, it can be said that the neutral white $(4000 \mathrm{~K})$ space was perceived more positively than the space lit with correlated color in proportion to correlated color temperatures.

Compared to other studies that use technology as a tool to perceive the environment, it can be admitted that augmented reality - compared with methods like animation - performs more accurately in forming the spatial perception of audiences. The results obtained about the environmental color differ from those of other studies. For example, Hidayetoglu et al.'s (2012) research in Turkey showed that participants were more inclined to use the red color in interior spaces, whereas the present research participants used the white color. The author believes that the reason lies in the cultural and social differences, and this is worth developing and investigating in future research. Regarding the effect of environmental color on readability, the use of light and neutral colors was more agreed upon in most of the studies such as Baker (1986) and Mahnke (1983), and the present research achieved quite similar results.

As mentioned earlier, the present study reviewed and analyzed the simultaneous effect of lights and colors on the environmental perception and legibility. The analytics suggested that attractiveness had the greatest effect on the legibility in both light and color variables. This could be attributed to the fact that respondents would fond the concept of attractiveness more easily conceivable than the other two, namely sense of invitation and navigation. In fact, it can be claimed that the majority of participants would prefer to be in more visually attractive environments considering the two parameters of light and color. Consequently, attractiveness is deemed more influential in increasing the legibility of the surroundings to the bystanders. It must be mentioned that users preferred neutral colors and lights, which in turn implies that neutral environments are more visually attractive.

Subsequently, the variable of gender was of equal weight to find attractiveness as the most important parameter in measuring the legibility of the environment, and the difference between the choices made by either gender group was in fact insignificant. Regarding the use of augmented reality technology, the participants unanimously stated that it creates a more realistic experience of the surroundings compared to pictures and animation. It was in fact proved that using this technology can yield more accurate results, which marks it as a proper replacement for older techniques.

In this study, the color, light level and correlated color temperature variables were restricted according to the type, size and intensity of variables. In further studies, the effects of low and high levels could be studied. Lastly, in this study only the effect of artificial light was studied. Future investigations would do well to similarly explore the effects of daylight. 
Declaration of Conflicting Interests: The author(s) declared no potential conflicts of interest with respect to the research, authorship, and/or publication of this article.

Funding: The authors received no financial support for the research, authorship, and/or publication of this article.

Acknowledgements: We are grateful to all the participants who have contributed to this study.

\section{References}

Akalin, A. (2009). Architecture and engineering students' evaluations of house façades. Journal of Environmental Psychology, 29(1), 124-132.

Azuma, R. (1997). A Survey of Augmented Reality. Cambridge: Massachusetts Institute of Technology.

Babin, B. J., Hardesty, D. M., \& Suter, T. A. (2003). Color and shopping intensions, theinterveving effects of price fairness and perceived affect. Journal BusinessResearch, 56(7), 541-551.

Baker, J. (1986). The role of the environment in marketing services. Chicago: American Marketing Association.

Bellizzi, J. A., Crowley, A. E., \& Hasty, R. (1983). The effects of color in store design. Journal of Retailing, 59(2), 21-45.

Bentley, I. (1985). Responsive Environments a Manual For Designers. London: Architectural Press.

Camgöz, N. Y. (2004). Effects of hue, saturation, and brightness. Color Research and Application Journal, 29(1), 20-28.

Canter, D. J. (1983). Synthesis of artificial lighting to satisfy multiple design criteria. Building and Environment, 18(2), 129-134.

Erem, O., \& Sener, G. (2008). Complexity versus sustainability in urban space: The case of Taksim Square. Journal of Istanbul, 21(2), 54-73.

Hidayetoglu, M. L., Yildirim, K., \& Akalin, A. (2012). The effects of color and light on indoor wayfinding and the evaluation. Journal of Environmental Psychology, 32(2), 50-58.

Höllerer, T., \& Feiner, S. (2004). Telegeoinformatics: Location-based computing and service. London: Taylor $\&$ Francis.

Kipper, G., \& Rampolla, J. (2013). Augmented reality: An emerging technologies guide to AR. London: Elsevier.

Knez, I., \& Kers, C. (2000). Effects of indoor lighting, gender and age on mood andcognitive performance. Environment and Behavior, 32(6), 817-831.

Kumoglu Suzer, O., Olgunturk, N., \& Guvenc, D. (2018). The effects of correlated colour temperature on wayfinding: A study in a virtual airport environment. Displays, 51(1), 9-29.

Lynch, K. (1960). Image of the city. Cambridge: Massachusetts Insttitute of TechnologyPress.

Mahdzar, S., \& Safari, H. (2014). Legibility as a Result of Geometry Space: Analyzing and Comparing Hypothetical Model and Existing Space by Space. Journal of Life Science, 67(6), 309-317.

Mahnke, F. H., \& Mahnke, R. H. (1993). Color and light in manmade environments. New York: Wiley.

Muci, S. (1994). Yapay aydınlatmanın mimari tasarımla ilis, kili yönleri. Trabzon: Karadeniz Technical University (Master thesis).

Osmann, J. P. (2002). using desktop virtual environment to investigate the role of landmarks. computers in 
human behavior journal, 34(2), 427-436.

Osmann, J. P., \& Berendt, B. (2002). Investigating distance knowledge using virtual environments. Environments and Behavior, 18(4), 178-193.

Pakzad, J., \& Bozorg, H. (2014). An introduction to environmental psychology for designers. Tehran: Armanshahr.

Paydar, M., \& Said, I. (2012). Commuters' Perception of Legibility and Complexity with Respect to Path Choice in Central Business District of Kuala Lumpur. international transaction journal of engineeringmanagement, 34(3), 345-362.

Pile, J. (1997). Color in interior design. Maidenhead: Mcgraw-Hill.

Quartier, K., Vanrie, J., \& Van Cleempoel, K. (2014). As real as it gets: What role does lighting have on consumer's perception of atmosphere, emotions and behaviour? Journal of Environmental Psychology, 56(1), $1-8$.

Read, M. A. (2003). Use of color in child care environments: Application of color forwayfinding and space definition in Alabama child care environments. Early Childhood Education Journal, 30(4), 233-239.

Stone, N. J. (2003). Environmental view and color for a simulated telemarketing task. Journal of Environmental Psychology, 23(1), 63-78.

Stone, N. J., \& English, A. J. (1998). Task type, posters, and workspace color on mood, satisfaction and performance. Journal of Environmental Psychology, 18(3), 175-185.

Tantanatewin, W., \& Inkarojrit, V. (2016). Effects of color and lighting on retail impression and identity. Journal of Environmental Psychology, 46, 197-205.

Tlauka, M., \& Wilson, P. N. (1996). Orientation free representation from navigation through a computer simulated environment. Environment and Behavior, 23(4), 647-664.

Valdez, P., \& Mehrabian, A. (1994). Effects of color on emotio. Journal of Environmental Psycology, 12(3), 384-409.

Wardono, P., Hibino, H., \& Koyama, S. (2012). Effects of Interior Colors, Lighting and Decors on Perceived. Social and Behavioral Sciences, 38(4), 362-372.

Witmer, B. G., Bailey, J. H., \& Knerr, B. W. (1996). Virtual spaces and real worldplaces: Transfer of route knowledge. International Journal of Human-ComputerStudies, 45(4), 413-428.

Yildirim, K., \& Akalin-Baskaya, A. (2007). Perceived crowding in a café/restaurant with different seating densities. Building and Environment, 3410-3417. Us dunto ium quia nes aces erias idiaest lam volore evel magnatem nit, tem dolupturesed evelest, suntur sapiend ipsandis verempor aboribusa parchil ipsunt, totatem 